\title{
FAKTOR-FAKTOR YANG MEMPENGARUHI KEPUTUSAN PEMBELIAN SAYUR DAN BUAH DI RITEL ONLINE (Suatu Kasus pada Konsumen Ritel Online di Jakarta)
}

\section{FACTORS AFFECTING DECISION BUYING OF VEGETABLES AND FRUITS ON ONLINE RETAIL (A Case on Consumers Online Retails in Jakarta)}

\author{
Ishfihana Rakasyifa*, Gema Wibawa Mukti \\ Program Studi Agribisnis Fakultas Pertanian Universitas Padjadjaran \\ J1. Raya Jatinangor Sumedang Km. 21 \\ *E-mail: ishfihana16001@mail.unpad.ac.id \\ (Diterima 23-12-2019; Disetujui 13-01-2020)
}

\begin{abstract}
ABSTRAK
Perkembangan di zaman revolusi industri 4.0 terjadi di berbagai sektor, termasuk di dalam sektor pertanian. Hal tersebut mendorong tumbuhnya ritel online untuk menjual hasil panen petani seperti sayur dan buah buah. Konsumen yang awalnya berbelanja di ritel tradisional atau modern mulai berbelanja sayur dan buah di ritel online. Perubahan ini dipengaruhi oleh adanya perubahan perilaku pembelian konsumen. Maka dari pada itu penelitian ini bertujuan untuk mengetahui: 1) Faktor yang mempengaruhi keputusan pembelian konsumen dalam berbelanja sayur dan buah di ritel online. 2) Besar pengaruh faktor-faktor tersebut terhadap keputusan pembelian sayur dan buah di ritel online. Metoda yang digunakan pada penelitian ini adalah survey per konsumen, responden diambil menggunakan Teknik non probability sampling. Jumlah populasi sampel pada penelitian ini dihitung menggunakan rumus Slovin. Hasil penelitian menunjukan bahwa. 1. Secara keseluruhan faktor tersebut memiliki kontribusi dan berpengaruh signifikan, secara parsial (terpisah) faktor yang berpengaruh secara signifikan yaitu faktor psikologis dan faktor pribadi, sedangkan faktor sosial dan budaya tidak berpengaruh signifikan. 2. Secara simultan (bersama-sama), faktor psikologis, pribadi, sosial, dan budaya dapat menjelaskan sebesar $54,4 \%$ terhadap keputusan pembelian sayur dan buah di ritel online.
\end{abstract}

Kata kunci: keputusan pembelian, faktor psikologis, faktor pribadi, faktor sosial, faktor budaya

\section{ABSTRACT}

Developments in industrial revolution 4.0 era occurred in various sectors, including in agricultural sector. This encourages the growth of online retailers to sell farmers' crops such as vegetables and fruit. Consumers who initially shop at traditional or modern retail start shopping for vegetables and fruit at online retail. This change is influenced by changes in consumer purchasing behavior. Therefore this study aims to determine: 1) Factors that influence consumer purchasing decisions in shopping for vegetables and fruit in online retail. 2) The influence of these factors on the decision to buy vegetables and fruit in online retail. The method used in this study is a survey per consumer, respondents were taken using non-probability sampling techniques. The total sample population in this study was calculated using the Slovin formula. The results showed that. 1. Overall these factors have a significant contribution and influence, partially (separately) factors that significantly influence the psychological factors and personal factors, while social and cultural factors have no significant effect. 2. Simultaneously (together), psychological, personal, social and cultural factors can explain $54.4 \%$ of the decision to purchase vegetables and fruit in online retail.

Keywords: purchasing decisions, psychological factors, personal factors, social factors, cultural factors 


\section{PENDAHULUAN}

Zaman sekarang merupakan zaman dimana semua bidang mengalami perubahan industri ke-4, atau disebut dengan revolusi industri 4.0. Revolusi industri 4.0 ditandai dengan meningkatnya penggunaan internet dan berkembangnya sektor ritel online. Menurut survey yang dilakukan oleh MIKTI dan Teknopreneur Indonesia yang didukung oleh Badan Ekonomi Kreatif RI, jumlah start-up di Indonesia yang sudah terverifikasi sampai pada tahun 2018 yaitu berjumlah $992 \quad$ startup. $\quad 35,48 \%$ diantaranya bergerak di bidang ritel online, 5,34\% di bidang fintech, 5,55\% di bidang game, dan $53,63 \%$ di bidang lainnya. Jumlah konsumen ritel online pun terus meningkat sejak tiga tahun terakhir, saat ini jumlah konsumen ritel online di Indonesia berjumlah $\quad 147.100 .000$ konsumen.

Pada sektor pertanian, ritel online muncul sebagai perantara bagi petani untuk menjual hasil panennya. Beberapa produk pertanian telah dijual secara online melalui perantara ritel online. Hal ini menjadi fenomena yang menarik karena seperti yang diketahui, produk pertanian memiliki karakteristik tersendiri yang berbeda dengan produk lainnya, yaitu bersifat mudah rusak dan volumenya tidak selalu seragam (I Gusti Bagus, 2011).

Konsumen yang berbelanja di ritel tradisional ataupun modern dengan alasan produknya dapat dilihat, dipilih, dan dibawa pulang langsung, sekarang mulai terbuka dengan opsi baru yaitu memercayai foto produk yang ditampilkan oleh ritel online, membelinya, lalu langsung dikirimkan ke rumah (Levy \& Weitz, 2004).

Adanya perubahan dalam pemilihan tempat masyarakat untuk berbelanja sayur dan buah ini dipengaruhi oleh adanya perubahan perilaku pembelian konsumen. Perubahan perilaku pembelian konsumen merupakan sebuah konsep yang menjawab pertanyaan apa, mengapa, kapan, bagaimana, dan dimana ketika seseorang ingin melakukan pembelian. Perilaku pembelian konsumen dipengaruhi oleh hal yang dipikirkan, dirasakan dan perilaku yang dilakukan oleh seorang individu sebelum atau ketika sedang melakukan pembelian apapun, produk ataupun jasa (Manali Khaniwale, 2015). Menurut Kotler dan Keller (2016), faktor-faktor yang mempengaruhi perilaku konsumen terdiri dari faktor budaya, sosial, pribadi, dan psikologis. Sedangkan proses pengambilan keputusan pembelian terbagi menjadi lima tahap 
yaitu pengenalan masalah, pencarian informasi, penilaian alternative, keputusan pembelian, dan perilaku pasca pembelian.

Berdasarkan pemaparan di atas, tujuan dari penelitian ini adalah untuk mengetahui: 1) Faktor apa yang mempengaruhi keputusan pembelian konsumen dalam berbelanja sayur dan buah di ritel online. 2) Besar pengaruh faktor-faktor tersebut terhadap keputusan pembelian sayur dan buah di ritel online.

\section{METODE PENELITIAN}

Penelitian dilakukan dengan metode survey pada konsumen yang pernah berbelanja produk sayur dan buah di ritel online dan berdomisili di Jakarta. Pemilihan lokasi ditentukan secara sengaja karena Jakarta merupakan kota dengan startup terbanyak menurut Mapping Startup di Indonesia tahun 2018 yang dilakukan oleh $\mathrm{MIKTI}^{3}$. Responden penelitian diambil menggunakan teknik non probability sampling. Jumlah populasi sampel pada penelitian ini dihitung menggunakan rumus Slovin, sehingga didapatkan jumlah sampel sebanyak 100 responden.

Pada penelitian ini terdapat variabel bebas dan variabel terikat. Variabel bebas terdiri dari faktor psikologis, faktor pribadi, faktor sosial, dan faktor budaya. Sedangkan variabel terikat merupakan keputusan pembelian.

Faktor psikologis sebagai bagian dari pengaruh lingkungan dimana ia tinggal dan hidup pada waktu sekarang tanpa mengabaikan pengaruh dimasa lampau atau antisipasinya pada waktu yang akan datang. Faktor psikologis terdiri dari persepsi, motivasi, pembelajaran, serta kepercayaan dan sikap (Lamb, dkk., 2011).

Faktor pribadi didefinisikan sebagai karakteristik psikologis seseorang yang berbeda dengan orang lain yang menyebabkan tanggapan yang relatif konsisten dan bertahan lama terhadap lingkungan. Karakteristik faktor pribadi terdiri dari kepribadian, pekerjaan, situasi ekonomi, dan gaya hidup (Lamb, dkk., 2011).

Faktor sosial terdiri dari grup, sosial media, keluarga, serta peran dan status. Faktor budaya adalah suatu cara hidup yang berkembang dan dimiliki bersama oleh sebuah kelompok orang dan diwariskan dari generasi ke generasi. Karakteristik faktor budaya terbagi menjadi budaya, sub budaya, dan kelas sosial (Lamb, dkk., 2011).

Pembuatan keputusan merupakan proses dimana seseorang diperlukan untuk 
membuat keputusan dari beberapa macam pilihan. Proses pengambilan keputusan terdiri dari pengenalan masalah, pencarian informasi, evaluasi alternatif, keputusan pembelian, dan sikap setelah pembelian (Lamb, dkk., 2011).

Teknik pengambilan data menggunakan kuisioner yang ditujukan bagi konsumen yang pernah berbelanja sayur dan buah di ritel online dan dengan studi literatur. Untuk skala pengukuran yang digunakan yaitu skala likert yang terbagi menjadi lima kriteria yaitu sangat setuju, setuju, ragu, tidak setuju, dan sangat tidak setuju.

Untuk menganalisis faktor-faktor yang mempengaruhi keputusan pembelian sayur dan buah di ritel online digunakan analisis regresi linear berganda dengan menggunakan bantuan program SPSS, dengan persamaan sebagai berikut:

$$
\mathrm{Y}=\mathrm{a}+b_{1} x_{1}+b_{2} x_{2}+b_{3} x_{3}+b_{4} x_{4}+\mathrm{e}
$$

Keterangan :

$\mathrm{Y}=$ Variabel terikat yaitu keputusan pembelian sayur dan buah di ritel online

$$
\begin{array}{ll}
\mathrm{a} & =\text { konstanta } \\
\mathrm{b}_{1}-\mathrm{b}_{4}= & \text { koefisien regresi } \mathrm{X}_{1} \text { sampai } \mathrm{X}_{4} \\
\mathrm{x}_{1} & =\text { Faktor Psikologi } \\
\mathrm{x}_{2} & =\text { Faktor Pribadi } \\
\mathrm{x}_{3} & =\text { Faktor Sosial } \\
\mathrm{x}_{4} & =\text { Faktor Budaya } \\
\mathrm{e} & =\text { standar error }
\end{array}
$$

\begin{tabular}{|c|c|c|c|c|}
\hline No & Variabel & Klasifikasi & $\begin{array}{l}\text { Jumlah } \\
\text { (Orang) }\end{array}$ & $\begin{array}{l}\text { Perse } \\
\text { ntase } \\
(\%)\end{array}$ \\
\hline \multirow[t]{2}{*}{1} & Jenis & Wanita & 91 & 91 \\
\hline & Kelamin & Pria & 9 & 9 \\
\hline \multicolumn{2}{|c|}{ Jumlah } & & 100 & 100 \\
\hline \multirow[t]{3}{*}{2} & Umur & $13-18$ & 0 & 0 \\
\hline & (Tahun) & $19-34$ & 53 & 53 \\
\hline & & $>34$ & 47 & 47 \\
\hline \multicolumn{2}{|c|}{ Jumlah } & & 100 & 100 \\
\hline \multirow[t]{5}{*}{3} & Domisili & Pusat & 5 & 5 \\
\hline & (Jakarta) & Utara & 7 & 7 \\
\hline & & Selatan & 40 & 40 \\
\hline & & Timur & 44 & 44 \\
\hline & & Barat & 4 & 4 \\
\hline \multicolumn{2}{|c|}{ Jumlah } & & 100 & 100 \\
\hline \multirow[t]{9}{*}{4} & Pendapatan & $\begin{array}{l}\leq \quad \mathrm{Rp} \\
1.500 .000,-\end{array}$ & 6 & 6 \\
\hline & & & 4 & 4 \\
\hline & & $1.500 .001-$ & & \\
\hline & & $\begin{array}{l}\text { Rp. } \\
3.000 .000\end{array}$ & & \\
\hline & & & 8 & 8 \\
\hline & & $3.000 .001-$ & & \\
\hline & & Rp. & & \\
\hline & & 4.500 .000 & & \\
\hline & & $\begin{array}{l}\geq \quad \text { Rp. } \\
4.500 .001\end{array}$ & 82 & 82 \\
\hline \multicolumn{2}{|c|}{ Jumlah } & & 100 & 100 \\
\hline \multirow[t]{9}{*}{5} & Status & Wanita & 61 & 61 \\
\hline & Pernikahan & Sudah & & \\
\hline & & Menikah & & \\
\hline & & Wanita & 30 & 30 \\
\hline & & Belum & & \\
\hline & & Menikah & & \\
\hline & & Pria Sudah & 7 & 7 \\
\hline & & Menikah & & \\
\hline & & $\begin{array}{l}\text { Pria Belum } \\
\text { Menikah }\end{array}$ & 2 & 2 \\
\hline \multicolumn{2}{|c|}{ Jumlah } & & 100 & 100 \\
\hline \multirow[t]{3}{*}{6} & Frekuensi & $<1$ Kali & 57 & 57 \\
\hline & berbelanja & $1-3$ Kali & 29 & 29 \\
\hline & $\begin{array}{ll}\text { sayur dan } \\
\text { buah di ritel } \\
\text { online }\end{array}$ & $>3$ Kali & 14 & 14 \\
\hline \multicolumn{2}{|c|}{ Jumlah } & & 100 & 100 \\
\hline
\end{tabular}

\section{HASIL DAN PEMBAHASAN}

\section{Karakteristik Konsumen}

Tabel berikut ini menjelaskan karakteristik responden konsumen yang berbelanja sayur dan buah di ritel online.

\section{Tabel 1. Karaktertistik Konsumen}

Sumber: Analisis Data Primer (2019) 
Berdasarkan Tabel 1. dapat dilihat berdasarkan pengelompokkan jenis kelamin, terdapat $91 \%$ wanita dan $9 \%$ pria responden yang berbelanja sayur dan buah di ritel online. Hal ini menunjukan bahwa sebagian besar kegiatan berbelanja sayur dan buah di ritel online dilakukan oleh wanita. Berdasarkan karakteristik usia, persentase tertinggi konsumen berusia 19 - 34 tahun, yaitu sebesar 53\%. Sebagian besar responden berdomisili di Jakarta Timur dengan persentase $44 \%$. Dari segi pendapatan, $\quad 82 \% \quad$ responden berpendapatan di atas Rp. 4.500.000. Hal ini dikarenakan dengan pendapatan yang lebih besar, konsumen dapat menyisihkan uangnya untuk membeli sayur dan buah di ritel online.

Menurut status pernikahannya, persentase tertinggi ditempati oleh wanita yang sudah menikah. Menurut hasil penelitian Sisca (2014), hal tersebut dikarenakan adanya kecenderungan perempuan yang telah menikah memiliki tanggung jawab untuk menjaga dan memenuhi kebutuhan keluarganya, dan menyediakan waktu khusus untuk berbelanja kebutuhan konsumsi keluarga. Sebagian besar konsumen berbelanja sayur dan buah kurang dari satu kali dalam satu bulan, yaitu dengan persentase sebesar $57 \%$.

\section{Uji Validitas}

Berikut ini merupakan hasil pengolahan data tanggapan konsumen terhadap variabel faktor budaya yang dihitung sesuai dengan kriteria yang telah ditetapkan. Hasil pengolahan disajikan dalam tabel 2. sebagai berikut

Tabel 2. Hasil Uji Validitas

\begin{tabular}{|c|c|c|c|c|}
\hline Variabel & $\begin{array}{l}\text { Ite } \\
\mathrm{m}\end{array}$ & $\begin{array}{l}\text { Koef } \\
\text { isien } \\
\text { Vali } \\
\text { ditas }\end{array}$ & rtabel & $\begin{array}{l}\text { Keterang } \\
\text { an }\end{array}$ \\
\hline \multirow[t]{4}{*}{ Psikologis } & $\mathrm{X} 11$ & $\begin{array}{l}0,66 \\
8\end{array}$ & $\begin{array}{l}0,194 \\
6\end{array}$ & Valid \\
\hline & $\mathrm{X} 12$ & $\begin{array}{l}0,77 \\
7\end{array}$ & $\begin{array}{l}0,194 \\
6\end{array}$ & Valid \\
\hline & $\mathrm{X} 13$ & $\begin{array}{l}0,79 \\
5\end{array}$ & $\begin{array}{l}0,194 \\
6\end{array}$ & Valid \\
\hline & X14 & $\begin{array}{l}0,71 \\
1\end{array}$ & $\begin{array}{l}0,194 \\
6\end{array}$ & Valid \\
\hline \multirow[t]{4}{*}{ Pribadi } & $\mathrm{X} 21$ & $\begin{array}{l}0,66 \\
8\end{array}$ & $\begin{array}{l}0,194 \\
6\end{array}$ & Valid \\
\hline & $\mathrm{X} 22$ & $\begin{array}{l}0,77 \\
7\end{array}$ & $\begin{array}{l}0,194 \\
6\end{array}$ & Valid \\
\hline & $\mathrm{X} 23$ & $\begin{array}{l}0,79 \\
5 \\
\end{array}$ & $\begin{array}{l}0,194 \\
6\end{array}$ & Valid \\
\hline & $\mathrm{X} 24$ & $\begin{array}{l}0,71 \\
1 \\
\end{array}$ & $\begin{array}{l}0,194 \\
6 \\
\end{array}$ & Valid \\
\hline \multirow[t]{5}{*}{ Sosial } & $\mathrm{X} 31$ & $\begin{array}{l}0,72 \\
7\end{array}$ & $\begin{array}{l}0,194 \\
6\end{array}$ & Valid \\
\hline & X32 & $\begin{array}{l}0,84 \\
7\end{array}$ & $\begin{array}{l}0,194 \\
6\end{array}$ & Valid \\
\hline & X33 & $\begin{array}{l}0,78 \\
9 \\
\end{array}$ & $\begin{array}{l}0,194 \\
6 \\
\end{array}$ & Valid \\
\hline & X34 & $\begin{array}{l}0,82 \\
0\end{array}$ & $\begin{array}{l}0,194 \\
6\end{array}$ & Valid \\
\hline & $\mathrm{X} 35$ & $\begin{array}{l}0,76 \\
0\end{array}$ & $\begin{array}{l}0,194 \\
6\end{array}$ & Valid \\
\hline \multirow[t]{5}{*}{ Budaya } & $\mathrm{X} 41$ & $\begin{array}{l}0,69 \\
1\end{array}$ & $\begin{array}{l}0,194 \\
6\end{array}$ & Valid \\
\hline & $\mathrm{X} 42$ & $\begin{array}{l}0,50 \\
9 \\
\end{array}$ & $\begin{array}{l}0,194 \\
6\end{array}$ & Valid \\
\hline & $\mathrm{X} 43$ & $\begin{array}{l}0,69 \\
6\end{array}$ & $\begin{array}{l}0,194 \\
6\end{array}$ & Valid \\
\hline & $\mathrm{X} 44$ & $\begin{array}{l}0,69 \\
5\end{array}$ & $\begin{array}{l}0,194 \\
6\end{array}$ & Valid \\
\hline & $\mathrm{X} 45$ & $\begin{array}{l}0,70 \\
2\end{array}$ & $\begin{array}{l}0,194 \\
6 \\
\end{array}$ & Valid \\
\hline $\begin{array}{l}\text { Keputusan } \\
\text { Pembelian }\end{array}$ & Y11 & $\begin{array}{l}0,58 \\
2\end{array}$ & $\begin{array}{l}0,194 \\
6\end{array}$ & Valid \\
\hline
\end{tabular}




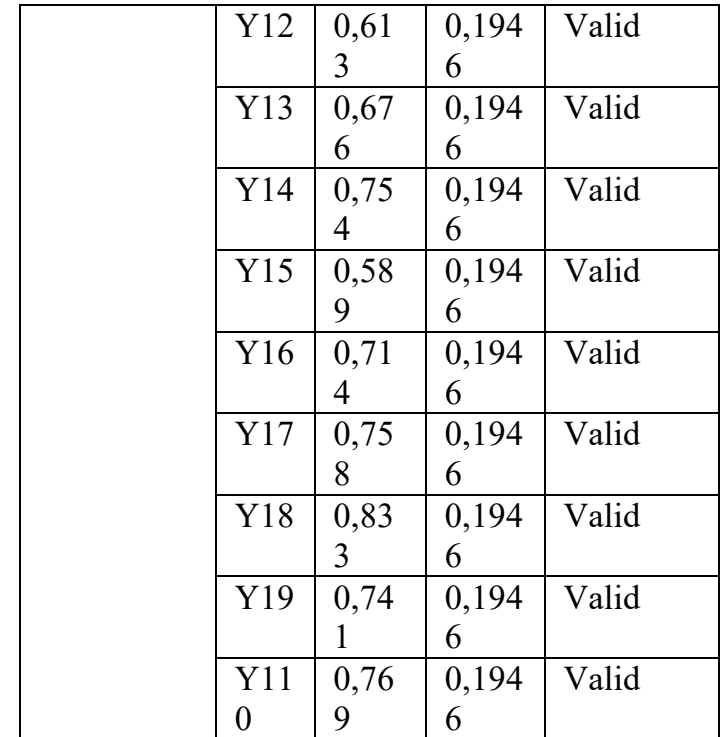

Sumber: Analisis Data Primer (2019)

Berdasarkan hasil uji validitas pada tabel 2. di atas, terlihat bahwa seluruh item dalam kuisioner menghasilkan nilai koefisien validitas lebih besar daripada nilai $r$ tabel dengan tingkat signifikansi 5\%. Sehingga dapat disimpulkan bahwa item-item pernyataan dalam kuisioner tersebut valid dan dapat digunakan untuk mengukur variabel keputusan pembelian dan akan mampu menghasilkan variabel yang akurat sesuai dengan tujuan penelitian.

\section{Uji Reliabilitas}

Berikut ini merupakan hasil pengolahan data tanggapan konsumen terhadap variabel faktor budaya yang dihitung sesuai dengan kriteria yang telah ditetapkan. Hasil pengolahan disajikan dalam tabel 3. sebagai berikut.
Tabel 3. Hasil Uji Reliabilitas

\begin{tabular}{|l|l|l|l|}
\hline Variabel & $\begin{array}{l}\text { Alpha } \\
\text { Cronbach } \\
(\alpha)\end{array}$ & $\begin{array}{l}\text { Titik } \\
\text { Minimum }\end{array}$ & $\begin{array}{l}\text { Keterang } \\
\text { an }\end{array}$ \\
\hline Psikologis & 0,716 & 0,60 & Reliabel \\
\hline Pribadi & 0,849 & 0,60 & Reliabel \\
\hline Sosial & 0,679 & 0,60 & Reliabel \\
\hline Budaya & 0,706 & 0,60 & Reliabel \\
\hline $\begin{array}{l}\text { Keputusan } \\
\text { Pembelian }\end{array}$ & 0,884 & 0,60 & Reliabel \\
\hline Sumb Anl
\end{tabular}

Sumber: Analisis Data Primer (2019)

Pada penelitian ini, uji reliabilitas alpha Cronbach dilakukan untuk memastikan bahwa data yang digunakan valid dan reliabel. Kuisioner dikatakan reliabel jika nilai Alpha Cronbach bernilai lebih besar dari 0,60 $(>0,60)$. Berdasarkan tabel 3., dapat diketahui bahwa masingmasing variabel pada kuisioner dinyatakan reliabel karena menghasilkan nilai alpha Cronbach $(\alpha)$ lebih besar dari 0,60 .

\section{Uji Asumsi Klasik}

Uji Normalitas

Uji Normalitas bertujuan untuk mengetahui apakah data yang dihimpun berdistribusi normal atau tidak. Model regresi dinilai baik jika data berdistribusi normal. Pada penelitian ini uji normalitas yang digunakan adalah uji normalitas Kolmogorov Smirnov. 
Tabel 4. Hasil Uji One-Sample KolmogorovSmirnov

\begin{tabular}{|ll|l|}
\hline & & $\begin{array}{l}\text { Unstandardized } \\
\text { Residual }\end{array}$ \\
\hline $\mathrm{N}$ & & 100 \\
Normal & Mean & 0,0000000 \\
Parameters $^{\mathrm{a}, \mathrm{b}}$ & & 3,97428541 \\
& Std. & Deviation \\
Most & Absolute & 0,076 \\
Extreme & & \\
Differences & & \\
& Positive & 0,044 \\
Test Statistic & Negative & $-0,076$ \\
Asymp. Sig. & & 0,076 \\
(2-tailed) & & 0,160 \\
\hline
\end{tabular}

Sumber: Analisis Data Primer (2019)

$$
\text { Berdasarkan hasil Uji }
$$

Kolmogorov-Smirnov pada Tabel 4, dapat dilihat bahwa angka signifikansi residual sebesar 0,160. Dengan demikian, bahwa dapat disimpulkan bahwa variabel dalam penelitian ini berdistribusi normal karena nilai residual lebih besar dari nilai signifikansinya $(0,160>0,05)$.

Uji Multikolinearitas

Uji Multikolinearitas diperlukan untuk mengetahui bahwa model regresi memiliki korelasi antara variabel independent atau variabel bebas atau tidak.

Tabel 4. Hasil Uji Mutikolinearitas Coefficients

\begin{tabular}{|c|c|c|}
\hline \multirow[t]{2}{*}{ Model } & \multicolumn{2}{|c|}{ Collinearity Statistic } \\
\hline & Tolerance & VIF \\
\hline Faktor Psikologi (X1) & 0.586 & 1.707 \\
\hline Faktor Pribadi (X2) & 0.530 & 1.887 \\
\hline Faktor Sosial (X3) & 0.535 & 1.870 \\
\hline Faktor Budaya (X4) & 0.545 & 1.833 \\
\hline \multicolumn{3}{|c|}{ Sumber: Analisis Data Primer (2019) } \\
\hline Berdasarkan & hasi & \\
\hline
\end{tabular}

multikolinearitas pada tabel 4. di atas, dapat diketahui bahwa nilai tolerance yang dihasilkan seluruh variable bernilai lebih besar dari $0,10(>0,10)$ dan nilai VIF lebih kecil dari 10,00 $(<10,00)$. Sehingga dapat disimpulkan bahwa tidak terjadi multikolinearitas dalam model regresi. Dengan demikian variabel Faktor Psikologi, Faktor Pribadi, Faktor Sosial dan Faktor Budaya dapat digunakan sebagai variabel independent dan sebagai prodiktor yang tidak bias.

Uji Heteroskedastisitas

Uji heteroskedastisitas bertujuan untuk menguji apakah model regresi terjadi ketidaksamaan varians dari residual satu pengamatan ke pengamatan yang lain. Dalam penelitian ini, uji yang dilakukan untuk mengetahui adanya heteroskedastisitas pada model regresi adalah menggunakan Grafik Scatterplots.

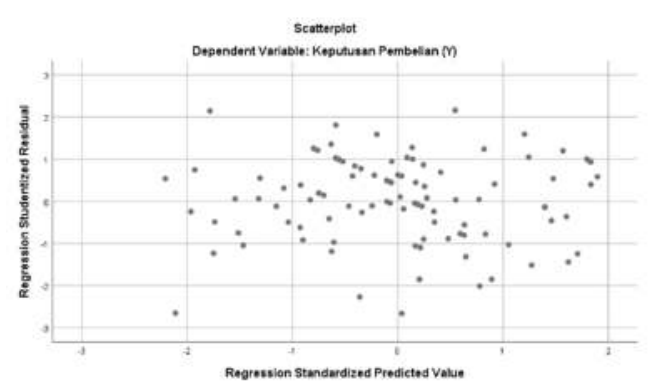

Gambar 1. Grafik Scatterplots Sumber: Analisis Data Primer (2019)

Berdasarkan grafik Scatterplot di atas, terlihat bahwa titik-titik bersifat menyebar dan tidak memiliki pola tertentu. Titik-titik pada grafik berada di atas dan di bawah angka 0 pada sumbu Y. 


\section{Uji Regresi Linear Berganda}

Berdasarkan hasil analisis data, dapat dirumuskan persamaan regresi linear berganda untuk faktor-faktor yang mempengaruhi keputusan pembelian sayur dan buah di ritel online adalah sebagai berikut:

$\mathrm{Y}=\mathrm{a}+b_{1} x_{1}+b_{2} x_{2}+b_{3} x_{3}+b_{4} x_{4}+\mathrm{e}$

$\mathrm{Y}=15,681+1,016 \mathrm{x}_{1}+0,461 \mathrm{x}_{2}+(-$

$0,011) \mathrm{x}_{3}+(-0,049) \mathrm{x}_{4}+2,592$

Keterangan :

$\mathrm{Y}=$ Variabel terikat yaitu keputusan

pembelian sayur dan buah di ritel online

$\mathrm{a}=$ konstanta

$\mathrm{b}_{1}-\mathrm{b}_{4}=$ koefisien regresi $\mathrm{X}_{1}$ sampai $\mathrm{X}_{4}$

$\mathrm{x}_{1}=$ Faktor Psikologi

$\mathrm{x}_{2}=$ Faktor Pribadi

$\mathrm{x}_{3}=$ Faktor Sosial

$\mathrm{x}_{4}=$ Faktor Budaya

$\mathrm{e}=$ standar error

Dari hasil analisis regresi di atas, dapat dijelaskan bahwa:

a. Diketahui bahwa nilai konstanta 15,681, artinya jika tidak ada pengaruh $\mathrm{x}_{1}, \mathrm{x}_{2}, \mathrm{x}_{3}$, dan $\mathrm{x}_{4}$ diabaikan, maka nilai keputusan pembelian sayur dan buah di ritel online sebesar 15,681.

b. Variabel Faktor Psikologi ( $\left.\mathrm{x}_{1}\right)$ memiliki nilai 1,016. Artinya, jika terjadi kenaikan variabel faktor psikologi sebesar satu satuan, maka akan menaikkan nilai keputusan pembelian sebesar 1,016 satuan. Dengan asumsi variabel lain bernilai tetap.

c. Variabel Faktor Pribadi $\left(\mathrm{x}_{2}\right)$ memiliki nilai 0,461. Artinya, jika terjadi kenaikan variabel faktor pribadi sebesar satu satuan, maka akan menaikkan nilai keputusan pembelian sebesar 0,461 satuan. Dengan asumsi variabel lain tetap.

d. Variabel Faktor Sosial $\left(x_{3}\right)$ memiliki nilai - 0,011. Artinya, jika terjadi kenaikan variabel faktor sosial sebesar satu satuan, maka akan menurunkan nilai keputusan pembelian sebesar 0,011 satuan. Dengan asumsi variabel lain tetap.

e. Variabel Faktor Budaya $\left(\mathrm{x}_{4}\right)$ memiliki nilai - 0,049. Artinya, jika terjadi kenaikan variabel faktor budaya sebesar satu satuan, maka akan menurunkan nilai keputusan pembelian sebesar 0,049. Dengan asumsi variabel lain tetap.

\section{Uji F}

Uji F bertujuan untuk mengetahui pengaruh variabel bebas secara bersamasama (simultan) terhadap variabel terikat. Uji $\mathrm{F}$ dilakukan dengan membandingkan nilai $F$ hitung dengan $F$ tabel untuk menguji signifikansi dari analisis regresi yang sudah didapatkan. 
Tabel 5. Hasil Uji F

\begin{tabular}{llll}
\hline Model & $\begin{array}{l}\text { Mean } \\
\text { Square }\end{array}$ & F & Sig. \\
\hline $\begin{array}{l}\text { Regression } \\
\text { Residual }\end{array}$ & 466.803 & 28.360 & $.000^{\mathrm{b}}$ \\
Total & 16.460 & & \\
\hline
\end{tabular}

Sumber: Analisis Data Primer (2019)

Berdasarkan Tabel 16. di atas, diperoleh nilai $\mathrm{F}$ hitung sebesar 28,360.

Diketahui bahwa nilai $\mathrm{F}$ tabel dengan derajat kebebasan pada $\alpha(0.05)$ adalah sebesar 2,467. Dengan demikian nilai $\mathrm{F}$ Hitung $(28,360)>$ F Tabel $(2,467)$. Dan nilai signifikansi yang didapatkan berdasarkan pengolahan data yaitu 0,000 , dimana nilai tersebut lebih kecil dari 0,05. Dari hasil pengolahan data tersebut dapat disimpulkan bahwa terdapat pengaruh seluruh variabel bebas secara simultan yang signifikan terhadap variabel terikat, artinya faktor psikologis, faktor pribadi, faktor sosial, dan budaya berpengaruh secara simultan yang signifikan terhadap keputusan pembelian sayur dan buah di ritel online.

\section{Uji t}

Uji t digunakan untuk mengetahui pengaruh masing-masing variabel bebas secara parsial terhadap variabel terikat. Diketahui bahwa nilai t tabel dengan $\alpha=$ 0,05 adalah sebesar 1,661, sedangkan nilai t hitung dapat dilihat pada tabel 6 .
Tabel 6. Hasil Uji t

\begin{tabular}{lll}
\hline Variabel & $\mathrm{t}$ hitung & $\mathrm{t}$ tabel \\
\hline Faktor Psikologi (X1) & 5.291 & 1,661 \\
Faktor Pribadi (X2) & 3.718 & 1,661 \\
Faktor Sosial (X3) & -.067 & 1,661 \\
Faktor Budaya (X4) & -.313 & 1,661 \\
\hline
\end{tabular}

Sumber: Analisis Data Primer (2018)

Berdasarkan tabel 6., maka berikut ini hasil uji t berdasarkan pengolahan data pada masing-masing variabel:

a. Faktor Psikologi

Berdasarkan data yang telah diolah, diperoleh bahwa nilai $\mathrm{t}$ hitung sebesar 5,291. Nilai tersebut lebih besar daripada nilai t tabel, yaitu sebesar 1,661. Dan nilai signifikansi yang diperoleh yaitu 0,000 , nilai tersebut lebih kecil dari 0,05 $(<0,05)$. Maka dapat disimpulkan bahwa secara parsial faktor psikologi berpengaruh positif dan signifikan terhadap keputusan pembelian sayur dan buah di ritel online. . Faktor psikologis meliputi motivasi, persepsi, pembelajaran, serta kepercayaan dan sikap.

- Motivasi:

Konsumen berbelanja sayur dan buah di ritel online karena konsumen memiliki motivasi untuk memenuhi kebutuhan hidupnya dan keluarganya. Berkaitan dengan responden pada penelitian ini sebagian besar merupakan wanita yang sudah menikah, dimana dalam sebuah keluarga yang berperan untuk berbelanja memenuhi kebutuhan makanan dan 
mengatur konsumsi rumah tangga berada pada seorang ibu atau istri. Dengan berbelanja sayur dan buah dapat memenuhi kebutuhan makanan keluarga dan kebutuhan gizi keluarga.

- Persepsi

Konsumen memiliki persepsi yang kuat bahwa mereka berbelanja sayur dan buah di ritel online karena ingin hidup sehat dengan mengonsumsi sayur dan buah. Sayur dan buah sangat bermanfaat untuk memenuhi zat gizi yang dibutuhkan tubuh.

- Pembelajaran

Dengan berbelanja sayur dan buah online, konsumen mempelajari bahwa dengan berbelanja sayur dan buah di ritel online mereka dapat melakukan kebiasaan yang lebih baik karena dapat mengonsumsi sayur dan buah secara rutin. Hal ini berhubungan dengan persepsi konsumen akan hidup sehat dengan mengonsumsi sayur dan buah.

- Kepercayaan dan Sikap

Konsumen mempercayai testimoni orang lain bahwa berbelanja sayur dan buah di ritel online lebih memiliki banyak kelebihan daripada berbelanja di tempat lain. Sejalan dengan penelitian Dialus (2018), bahwa testimoni yang diberikan oleh pembeli sebelumnya merupakan salah satu acuan untuk menentukan keputusan pembelian suatu barang dalam berbelanja di saluran belanja online.

\section{b. Faktor Pribadi}

Setelah dilakukan uji terhadap faktor pribadi, diperoleh bahwa nilai t hitung sebesar 3,718. Nilai tersebut lebih besar daripada nilai t tabel, yaitu sebesar 1,661. Dan nilai signifikansi yang diperoleh yaitu 0,000, nilai tersebut lebih kecil dari 0,05 $(<0,05)$. Maka dapat disimpulkan bahwa secara parsial faktor pribadi berpengaruh positif dan signifikan terhadap keputusan pembelian sayur dan buah di ritel online. Faktor pribadi dalam keputusan pembelian terdiri dari beberapa indikator yaitu kepribadian, pekerjaan, umur dan fase kehidupan, situasi ekonomi, dan gaya hidup.

- Kepribadian

Konsumen mengakui bahwa berbelanja sayur dan buah di ritel online sesuai dengan dirinya. Kesesuaian yang dimaksud adalah kesesuaian antara nilai yang dianut konsumen tersebut dengan proses jual beli sayur dan buah ataupun dengan nilai yang dibawa oleh peritel online itu sendiri.

- Pekerjaan

Berdasarkan responden pada penelitian ini, sebagian besar merupakan wanita yang sudah menikah. Maka, 
pemenuhan kebutuhan pada suatu keluarga bergantung pada pendapatan keluarganya, terutama pendapatan orang tua. Pendapatan merupakan faktor yang menentukan kualitas dan kuantitas makanan yang dikonsumsi. Semakin tinggi pendapatan maka semakin besar peluang untuk memilih makanan yang baik, yaitu sayur dan buah (Rachman, dkk., 2017).

- Umur dan Fase Kehidupan

Konsumen menyetujui bahwa keputusannya untuk berbelanja sayur dan buah di ritel online dipengaruhi oleh umur dan fase kehidupannya. Menurut penelitian Lestari, (2013), semakin dewasa usia seseorang, maka kecenderungannya untuk mengonsumsi sayur dan buah menjadi lebih tinggi. Dari aspek fase kehidupan, berdasarkan responden pada penelitian ini, jumlah responden yang sudah menikah lebih banyak daripada yang belum menikah, dan jumlah tersebut didominasi oleh wanita. Seringkali seseorang yang telah memasuki fase pernikahan tidak hanya membeli sebuah produk untuk dirinya sendiri, tetapi juga untuk anggota keluarganya. Hal ini dikarenakan konsumen tersebut menginginkan anggota keluarganya mengonsumsi hal-hal yang baik dan menyehatkan bagi tubuh, dan sayur dan buah merupakan salah satunya.

- Situasi Ekonomi

Dari segi ekonomi, konsumen mengakui bahwa berbelanja sayur dan buah di ritel online sesuai dengan situasi ekonominya. Artinya, seseorang melakukan kegiatan belanja sayur dan buah di ritel online karena uang yang dikeluarkan untuk hal tersebut setimpal dengan hal yang didapatkannya dan sesuai dengan situasi ekonominya saat itu.

- Gaya Hidup

Konsumen menyetujui bahwa berbelanja sayur dan buah di ritel online merupakan gaya hidupnya. Saat ini, banyak orang yang menganut gaya hidup sehat. Hal ini sejalan dengan penelitian yang dilakukan oleh Sukma (2012) yang mengatakan bahwa terdapat hubungan positif yang sangat signifikan antara kesadaran kesehatan dengan sikap konsumen pada makanan organik melalui gaya hidup sehat.

\section{c. Faktor Sosial}

Uji t pada variabel faktor sosial menghasilkan nilai $\mathrm{t}$ hitung sebesar 0,067, lebih kecil daripada $t$ tabel. Sedangkan signifikansi yang diperoleh yaitu 0,947 , lebih besar dari $0,05(>0,05)$. Maka dapat disimpulkan bahwa variabel 
faktor sosial berpengaruh dan tidak signifikan terhadap variabel keputusan pembelian sayur dan buah di ritel online.

Berkaitan dengan karakteristik responden dalam penelitian ini, yaitu dimana sebagian besar responden berjenis wanita yang sudah menikah. Menurut Afrima (2014), wanita yang telah menikah memiliki kecenderungan bertanggung jawab untuk menjaga dan memenuhi kebutuhan keluarganya, dan menyediakan waktu khusus untuk berbelanja kebutuhan konsumsi keluarga. Sehingga apapun yang dikatakan maupun dilakukan oleh orang-orang di lingkungan sekitarnya, tidak berpengaruh signifikan bagi konsumen untuk melakukan keputusan pembelian selama konsumen mempercayai bahwa berbelanja sayur dan buah di ritel online merupakan keputusan yang terbaik.

\section{d. Faktor Budaya}

Pada variabel faktor sosial menghasilkan nilai $t$ hitung sebesar 0,313, lebih kecil daripada $\mathrm{t}$ tabel. Sedangkan signifikansi yang diperoleh yaitu 0,755 , lebih besar dari $0,05(>0,05)$. Maka dapat disimpulkan bahwa variabel faktor sosial berpengaruh dan tidak signifikan terhadap variabel keputusan pembelian sayur dan buah di ritel online.
Dalam berbelanja sayur dan buah di ritel online, budaya tidak berpengaruh signifikan terhadap keputusan pembelian sayur dan buah di ritel online. Di lokasi penelitian ini yaitu daerah Jakarta, terdiri dari banyak masyarakat yang berasal dari luar daerah, kebanyakan dari mereka berpindah dari desa ke Jakarta untuk memperbaiki ekonomi. Hal serupa disampaikan oleh narasumber dalam penelitian Marta (2014), bahwa di daerahnya (Pesisir Selatan, Padang) banyak yang menjadikan Jakarta sebagai tujuan merantau.

Untuk masuk ke lingkungan baru, maka diperlukan penerimaan terhadap budaya yang baru juga dan penyesuaian diri terhadap kelompok baru. Sehingga budaya di daerah asalnya tidak lagi berpengaruh secara signifikan di lingkungannya yang baru.

\section{Uji Koefisien Determinasi $\left(\mathbf{R}^{\mathbf{2}}\right)$}

Uji koefisien determinasi $\left(\mathrm{R}^{2}\right)$ bertujuan untuk mengukur seberapa jauh kemampuan variabel bebas mempengaruhi variabel terikat (Y). Uji ini dapat dilakukan jika hasil uji hipotesis (uji F) menyatakan bahwa variabel berpengaruh secara signifikan. 
Tabel 6. Hasil Uji Koefisien Determinasi $\left(\mathbf{R}^{\mathbf{2}}\right)$

\begin{tabular}{lllc}
\hline $\mathrm{R}$ & $\mathrm{R}$ & Adjusted & Std. Error of \\
& Square & R Square & the Estimate \\
\hline $.738^{\mathrm{a}}$ & .544 & .525 & 4.057
\end{tabular}

Sumber: Analisis Data Primer (2019)

Berdasarkan Tabel 6. di atas, dengan uji regresi linear diperoleh nilai koefisien determinasi $\left(\mathrm{R}^{2}\right)$ sebesar 0,544 atau 54,4\%. Hal ini menunjukan bahwa Faktor Psikologi, Faktor Pribadi, Faktor Sosial, dan Faktor Budaya dapat menjelaskan Keputusan pembelian sayur dan buah di ritel online sebesar 54,4\%. Sedangkan sisanya, yaitu sebesar 45,6\% lainnya dijelaskan oleh faktor-faktor yang tidak diteliti dalam penelitian ini.

\section{KESIMPULAN DAN SARAN}

Berdasarkan hasil penelitian yang telah dilakukan melalui analisis deskripif dengan menggunakan uji regresi linear berganda, dapat diambil kesimpulan sebagai berikut:

1. Faktor yang mempengaruhi keputusan pembelian sayur dan buah di ritel online adalah faktor psikologis, pribadi, sosial, dan budaya.

2. Secara parsial, faktor yang berpengaruh secara signifikan terhadap keputusan pembelian sayur dan buah di ritel online adalah faktor psikologis dan faktor pribadi, sedangkan faktor sosial dan faktor budaya berpengaruh secara tidak signifikan terhadap keputusan pembelian sayur dan buah di ritel online. Secara simultan, keputusan pembeli konsumen yang dipengaruhi oleh faktor psikologis, faktor pribadi, faktor sosial, dan faktor budaya berpengaruh signifikan terhadap keputusan pembelian sayur dan buah di ritel online. Sehingga jika seluruh faktor-faktor tersebut diperhatikan dengan baik secara bersamaan, maka akan semakin mempengaruhi keputusan pembelian sayur dan buah di ritel online. Faktor psikologis, pribadi, sosial, dan budaya dapat menjelaskan keputusan pembelian sayur dan buah di ritel online sebesar $54,4 \%$. Sedangkan sisanya dipengaruhi oleh faktor lain yang tidak diteliti dalam penelitian ini.

Berdasarkan hasil analisis penelitian, hasil pembahasan, dan kesimpulan maka saran yang dapat diberikan, yaitu:

1. Para peritel online menggencarkan sebuah gerakan untuk menginformasikan manfaat dari mengonsumsi sayur dan buah kepada masyarakat di masing-masing media sosial peritel secara berulang kali. Konten media sosial dikemas secara menarik dan diberikan contoh-contoh 
kasus yang dekat dengan masyarakat.

Sehingga dapat menarik perhatian masyarakat dan kemungkinan mendapatkan konsumen baru menjadi lebih besar.

2. Untuk penelitian selanjutnya, sebaiknya ditambahkan mengenai variabel atribut produk dan fasilitas yang ada pada ritel online itu sendiri, sehingga penelitian yang dilakukan dapat mendeskripsikan faktor yang mempengaruhi keputusan pembelian sayur dan buah dari perspektif produk dan ritel online.

3. Sebaiknya lokasi penelitian dilakukan juga di kota-kota lainnya, sehingga terkumpul mengenai faktor yang mempengaruhi keputusan pembelian sayur dan buah di ritel online di Indonesia.

\section{DAFTAR PUSTAKA}

Adiyanto, Reza, Ujang Sumarwan, dan Imam Teguh Sptono. 2017. Consumer Behavior Analysis in Choosing Conventional or Sharia Mortgage Product in Indonesia. Asian Social Science; Vol. 13, No. 8; 2017

A.Muri Yusuf. 2014. Metodologi Penelitian Kuantitatif, Kualitatif dan Penelitian Gabungan. Jakarta: Prenadamedia Group.

Arikunto, Suharsimi, 2002. Prosedur Penelitian Suatu Pendekatan Praktek. Jakarta. PT. Rineka Cipta
Asosiasi Pengguna Jasa Internet Indonesia. (2017). Laporan Survei Teknopreneur Indonesia dan Asosiasi Penyelenggara Jasa Internet Indonesia

Ayunita Nugrahaeni, D. , 2018, Modul Uji Validitas dan Reliabilitas, Universitas Diponegoro

Ba, S., \& Pavlou, P. A. (2002). Evidence of the Effect of Trust Building Technology in Electronic Markets: Price Premiums and Buyer Behavior. MIS Quarterly, 26(3), 243. https://doi.org/10.2307/4132332

Blomqvist A., Frida Lennartsson, Louise Nyman, 2015, Consumer Attitudes Towards Online Grocery Shopping, Jonkoping International Busines School.

Budi Puspitasari, N., Nugroho W P, S., Nilan Amyhorsea, D., \& Susanty, A. (2018). Consumer's Buying Decision-Making Process in ECommerce. E3S Web of Conferences, 31(September 2016), 11003. https://doi.org/10.1051/e3sconf/201 83111003

Burhan, Bungin. 2005. Metodelogi Penelitian Kuantitatif : Komunikasi, Ekonomi, dan Kebijakan Publik Serta Ilmu-Ilmu Sosial Lainnya. Kencana Prenada Media Group. Jakarta

Gusti Bagus I. , 2011, Peran Agroindustri dalam Pembangunan Pertanian, Singhadwala Edisi 44

Hanus Gabriela, 2016, Consumer Behaviour During Online Grocery Shopping, CBU International Conference on Innovation Science and Education.

Harlan, Johan., 2018, Analisis Regresi Linear, Jakarta: Penerbit Gunadarma

Idrus Muhammad, 2009, Metode Penelitian Ilmu Sosial Pendekatan 
Kualitatif dan Kuantitatif, Jakarta: Erlangga

Indah, K. , Mandala, K. 2015. Pengaruh Faktor Budaya, Sosial, Pribadi, Psikologis, dan Bauran Pemasaran Terhadap Keputusan Pembelian Kebaya Bordir pada Jegeg Ayu Boutique di Kuta, E-Jurnal Manajemen Universitas Udayana Vol. 4, No. 11, 2015: 3619 - 3645

Khaniwale Manali, 2015, Consumer Buying Behavior, International Journal of Innovation and Scientific Research Vol. 14 No. 2 Apr. 2015

Kotler, Philip, K. L. keller. (2016). Marketing Management Global Edition 15th Edition. (Vol. 15E). https://doi.org/10.1080/0891176090 3022556

Kotler, P., \& Armstrong, G. (2017).

Kotler_and_Armstrong_-

Principles_of_Marketing. $17^{\text {th }}$

Edition

Lamb, Charles W., Joseph F. Hair, \& Carl McDaniel (2011), Marketing, South-Western Cengage Learning, Mason-USA

Levy, Michael, Barton A. Weitz. 2004. Retailing Singapur:Mc-Graw Hill.

MIKTI (2018), Mapping dan Database Startup Indonesia 2018

Nurfiatiasari S., Atik Aprianingsih, 2017, A Pilot Study of Technology Adoption: An Analysis of Consumers' Preference on Future Online Grocery Service, The Asian Journal of Technology Management Vol. 10 No. 2 (2017): 74-89
Pierce, Jon L., T. Kostova, Kurt Dirks, 2003, The State of Psychological Ownership: Integrating and Extending a Century of Research

Ramadani Yalanda, Regina, 2019, Pengaruh Direct Marketing Terhadap Keputusan Pembelian Kopi Arabika Malabar Mountain Coffee

R. Kavitha, 2017, A Study on Consumers acuity towards online grocery shopping, IJCRT | Volume 5, Issue 4 December 2017

Singgih Santoso, 2010, Statistic Multivariat, Jakarta: Elex Media Komputindo

Singarimbun, Masri dan Sofian Effendi, 2006, Metode Penelitian Survei ( Editor ), LP3ES, Jakarta

Sudjana, Nana. 2004. Penilaian Hasil Proses Belajar Mengajar. Bandung: Remaja Rosdakarya.

Sugiyono, 2009, Metode Penelitian Kuantitatif, Kualitatif dan R\&D, Bandung : Alfabeta

Tetra Pax Index, 2019, Tetra Pak Indo Online Report

Vries, P. (2018). Escaping poverty. The origins of modern economic growth , 516 pages.

Wigand, Rolf T., 1997, Electronic Commerce: Definition, Theory, and Context

Yusuf Muri, 2013, Metode Penelitian Kuantitatif, Kualitatif, dan Penelitian Gabungan, Jakarta: Prenada Media 